\title{
Transcavernous Approach for Microsurgical Clipping of Ruptured Right Superior Cerebellar Artery Aneurysm with Cadaveric Stepwise Video Illustration
}

\author{
Edinson Najera ${ }^{1, *}$ Baha'eddin A. Muhsen ${ }^{1, *}$ Hamid Borghei-Razavi ${ }^{1}$ Michal obrzut ${ }^{1}$ Badih Adada ${ }^{1}$ \\ ${ }^{1}$ Department of Neurosurgery, Braathen Center, Cleveland Clinic \\ Florida, Weston, Florida, United States \\ J Neurol Surg B Skull Base 2022;83(suppl S3):e619-e620.

\begin{abstract}
Address for correspondence Badih Adada, MD, Department of Neurosurgery, Braathen Center, Cleveland Clinic Florida, 2950 Cleveland Clinic Boulevard, Weston, FL 33331-3609, United States (e-mail: ADADAB@ccf.org).
\end{abstract}

\begin{abstract}
Superior cerebellar artery (SCA) aneurysms are rare. The management options are not well defined. There is increasing role of endovascular treatment for all aneurysms, especially for aneurysms of the posterior circulation. However in some situations (wide base, dysmorphic features) coiling is not feasible. The surgical management of these aneurysms has its own distinct complexity and requires careful planning. The classic pterional or subtemporal approaches had its own limitation in proper visualization of

Keywords

- right superior cerebellar artery aneurysm

- microsurgical clipping

- cavernous sinus

- trans cavernous sinus approach the neurovascular anatomy.

In this video, we describe the technical nuances of transcavernous sinus approach for microsurgical clipping SCA and A-comm aneurysms. We present the case of a 67-yearold RHF who presented with ruptured right-sided SCA aneurysm. She complained of Headache, confusion, and double vision. On physical examination, she had no focal deficits and was Hunt and Hess grade 3. A brain computed tomography (CT) scan revealed a subarachnoid hemorrhage Fisher's grade 4 . A brain CT angiography (CTA) demonstrated an aneurysm at the origin of right SCA. The patient had failed attempt of endovascular coiling and she underwent microsurgical clipping.
\end{abstract}

www.thieme.com/skullbasevideos

www.thieme.com/jnlsbvideos

These authors contributed equally to this work.

received

May 1, 2020

accepted

October 31, 2020

published online

May 11, 2021
DOI https://doi.org/

10.1055/s-0041-1727178. ISSN 2193-6331.

\footnotetext{
(C) 2021. The Author(s).

This is an open access article published by Thieme under the terms of the Creative Commons Attribution-NonDerivative-NonCommercial-License, permitting copying and reproduction so long as the original work is given appropriate credit. Contents may not be used for commercial purposes, or adapted, remixed, transformed or built upon. (https://creativecommons.org/ licenses/by-nc-nd/4.0/) Georg Thieme Verlag KG, Rüdigerstraße 14, 70469 Stuttgart, Germany
} 
Stepwise demonstration of the approach with cadaveric anatomical dissection is illustrated. The technique presented here allows for safe clipping of the aneurysm through the cavernous sinus. The approach allows for good exposure of the aneurysm and the surrounding structures. Care is taken to visualize the perforators to avoid any devastating brain stem infarction during the clipping.

The transcavernous sinus is a robust approach with good visualization of the neurovascular structures allowing safe aneurysm clipping in this location.

The link to the video can be found at: https://youtu.be/oE-HyDASiKM.

Conflict of Interest

None declared. 